\title{
Microstructural and Compositional Characterisation of Chromate Pretreatment on Aluminium
}

\author{
M. Oki \\ Department of Mechanical Engineering, Landmark University, PMB 1001, Omu-Aran, 251101 Kwara State, Nigeria
}

Correspondence should be addressed to M. Oki; makanjuolaoki@justice.com

Received 7 July 2013; Accepted 19 September 2013

Academic Editors: A. V. Dos Santos and E. Ramous

Copyright (C) 2013 M. Oki. This is an open access article distributed under the Creative Commons Attribution License, which permits unrestricted use, distribution, and reproduction in any medium, provided the original work is properly cited.

Chromate conversion coating developed on aluminium has been examined using SEM/EDX and CTEM/EDX with a view to having further knowledge of its intrinsic surface, plan, and sectional morphologies which will aid the understanding of their roles in improved corrosion and adhesion properties of the underlying substrate. The surface consists of spherical clusters of particulate materials. The sections, however, reveal approximately parallel, linear features which terminate at or close to the metal/coating interface, while plan views show cell-like particulate features. The coating is composed of chromium and aluminium compounds, both, probably hydrated. For a conversion coating to fully replace its chromate counterpart, most of these features may have to be replicated in the nonchromium coating material which should contain nontoxic, leachable corrosion inhibiting species.

\section{Introduction}

Unfortunately, hexavalent chromium present in chromate conversion coating (CCC) formulations as well as in the dried coatings [1-6] has been listed as a possible carcinogen. Consequently, active investigations [1,7-14] are on processes and formulations to replace chromate's corrosion protective properties and improved adhesion of subsequently applied finishes on aluminium and other alloys. Such formulations include those based on noncarcinogens as $\mathrm{Zr}$ [7], $\mathrm{Zr} /$ titanium/phosphonic acid [10] and cerium [13, 14] based conversion coatings. Some of these have been patented and are being used in mild environments.

Although these and a number of alternative processes and formulations based on sol-gel chemistry are probably in the forefront as replacements, their performances lag [11] behind those of chromate conversion coatings.

In view of these shortcomings, the present study seeks to know more about the changes in microstructure and composition imparted on aluminium by a typical chromate conversion coating formulation for its outstanding performances in terms of improved corrosion resistance and adhesion. This knowledge will enhance the pursuit of more favourable results in advances from the search for suitable nonchromium replacements.

\section{Materials and Methods}

2.1. Materials. Aluminium specimens, of nominal composition, 0.002 wt. $\% \mathrm{Fe}, 0.002$ wt.\% $\mathrm{Cu}$, and 0.003 wt.\% Si, were prepared by cutting up as-received materials into spadelike electrodes of dimensions $10 \mathrm{~mm} \times 5 \mathrm{~mm} \times 0.5 \mathrm{~mm}$. The electrodes were electropolished according to the standard guide ASTM E1558-09 [15] rinsed in distilled water and dried in air. These electrodes were immersed for various periods in a conversion coating bath containing $7.5 \mathrm{~g} / \mathrm{L} \mathrm{Na}_{2} \mathrm{Cr}_{2} \mathrm{O}_{7}, 4 \mathrm{~g} / \mathrm{L}$ $\mathrm{CrO}_{3}$, and $1 \mathrm{~g} / \mathrm{L} \mathrm{NaF}$. All chemicals used are of analar grade.

2.2. Methods. Electropolished and conversion-coated specimens were examined directly and after platinum coating to enhance the surface features in an ISIDS130 Scanning electron microscope and elemental analysis of the coating obtained in the energy dispersive X-ray (EDX) facility attached to the microscope. Ultramicrotomed sections of the specimens were obtained using an LKB Ultratome III 8800 ultramicrotome and examined in a Philips 301 transmission electron microscope. Using the EDX facility attached to Philips EM400T transmission electron microscope and a probe size of $10 \mathrm{~nm}$, elemental composition of the coating was obtained at different regions from the coating/solution interface to the metal/coating interface. 


\section{Results and Discussions}

3.1. General Observation. Visual observation of the specimens which were treated for various times revealed that the reflective electropolished aluminium had changed progressively to golden yellow colour broadly indicating development of a coating. For specimens developed for 30 seconds, the reflective appearance of the substrate was sustained, but a greenish yellow tone was revealed. With increase in treatment time, the specimens showed increasingly golden yellow colouration which became brown after protracted treatment time. At face value, this suggests that film formation occurred with increase incorporation of $\mathrm{Cr}^{6+}$ species from the coating solution with time of treatment. In addition, micro- and macro-roughness associated with the film/solution and substrate/film interfaces may contribute to such appearance to the naked eye.

3.2. Surface Morphology. The surface features of an electropolished aluminium have been presented elsewhere [16]; however, apart from occasional cavities, there are no discernible striking features revealed within the resolution limits of the SEM.

After immersion in the coating solution for $30 \mathrm{~s}$, the specimen revealed a generally cracked surface morphology. It comprises of dark regions with lighter areas, where the film thickness is lower than that of its counterpart. Such morphological change in the lustrous aluminium substrate indicates an initial formation of a relatively nonuniform film over the macroscopic metal surface. In order to give rise to dark appearance, the secondary imaging electrons were probably preferentially absorbed in the relatively thick film materials. However, in the thinner regions, the detected electrons were of greater yield through more contribution from the underlying aluminium substrate. The crack widths assessed from the micrograph ranged from $20 \mathrm{~nm}$ to $30 \mathrm{~nm}$ although others may be of dimensions below the limit of resolution of the instrument.

Increase in time of treatment witnessed the formation of an apparently uniform conversion coating with increases in the crack morphology and their widths. Width sizes ranging from $500 \mathrm{~nm}$ for specimens treated for $120 \mathrm{~s}$ to about $900 \mathrm{~nm}$ for specimens treated for $180 \mathrm{~s}$ are discernible. Although features are not readily resolvable within the coatings demarcated by the so-called mud cracking, they appear to be relatively uniformly textured whereas the island of coating materials demarcated by the cracks became smaller in effective diameter as time of treatment increased.

Mudcracking has been described by various authors $[5,17]$ as a characteristics of the drying out of hydrated, probably gel-like deposits; however, it is possible that as the deposits agglomerate, shrinkage stresses increased, leading to increased crack widths as treatment time increased. Cracks which are characteristic of dried coatings were not detected in wet coatings examined in the conventional optical microscope. The later indicates that cracks evident in the conversion coatings are likely the result of shrinkage stresses generated during drying out of the coatings. Cracks in the coatings have been suggested to be beneficial [5] for paint

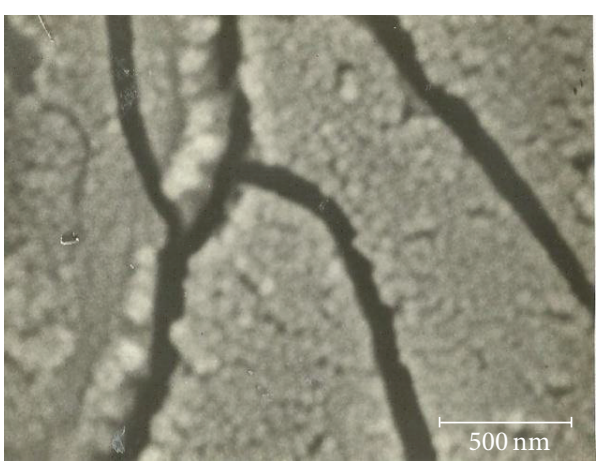

FIGURE 1: Scanning electron micrograph of aluminium treated in chromate bath for $120 \mathrm{~s}$ viewed in the high-resolution stage of the SEM.

adhesion as it allows for mechanical interlocking between the chromate coatings and subsequently applied organic finishes. In addition, cracks increase the surface area for $\mathrm{H}$-bonding and dispersion forces which contribute to improved adhesion between the coating and the molecules of the organic finishes.

Although microfeatures were not readily resolvable within the coatings examined in the lower stage of the SEM, examination in the high resolution stage reveals the surfaces of the specimens to be composed of approximately spherical particles; see Figure 1. The particles or perhaps groups of particles vary in sizes from about $20 \mathrm{~nm}$ to about $80 \mathrm{~nm}$. This suggests that the coating developed laterally over the microscopic metal surface by merging together of particulate conversion coating materials. Such microfeatures, which have been observed by others [5], in addition to cracks mentioned earlier, will contribute to improved paint adhesion by providing anchor sites for subsequently applied organic finishes.

3.3. Plan and Sectional Morphology. Irrespective of treatment times, the plan view of coatings stripped from aluminium substrates using mercuric chloride solution appears similar. However, it became increasingly difficult to resolve the features in the coatings stripped off specimens treated for relatively long periods. Thus, electron transparency was marred as a result of film thickening with increase time of treatment. After $15 \mathrm{~s}$ of treatment, the film (Figure 2), revealed a relatively coarse grain-like appearance with grains separated by relatively light regions. Additionally, evident within the grains are cell-like features of dark materials separated by light materials ranging in effective diameter from about $40 \mathrm{~nm}$ to $55 \mathrm{~nm}$. These suggest an initial preferential development of the coatings at or closely adjacent to the grain boundaries of the aluminium substrate which seemingly acted as the anodes in the electrochemical reaction leading to the deposition of hydrated Cr III oxide/hydroxide in the interior of the grains.

The nonuniformity in the initially deposited coating material is shown further in Figure 3, the ultramicrotomed section of the specimen, with the aluminium substrate displayed at the bottom of the micrograph where the initial electropolishing film has been replaced by a coating of about 


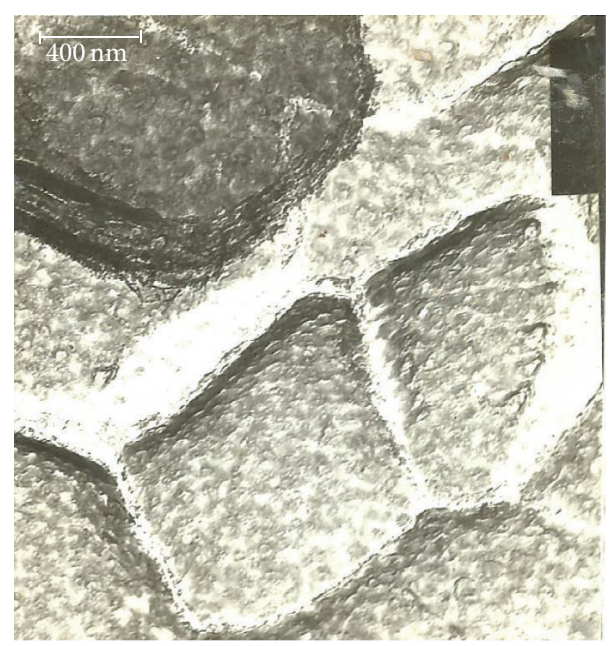

FIGURE 2: Transmission electron micrograph showing the plan view of a stripped coating developed on aluminium for $15 \mathrm{~s}$.

$50 \mathrm{~nm}$ in thickness. The coating obviously shows a variation in thickness over the length of the section indicating nonuniform growth pattern over the macroscopic metal surface. Increased treatment time witnessed increases in thickness of the coatings with relatively uniform surfaces.

The thickness of the coatings as measured from the transmission electron micrographs is $80 \mathrm{~nm}$ for specimens treated for $30 \mathrm{~s}, 200 \mathrm{~nm}$ for the specimens treated for $120 \mathrm{~s}$, Figure 4, whereas the specimens treated for $600 \mathrm{~s}$ are about $300 \mathrm{~nm}$ thick. The undulating features revealed in Figure 4 are related to the topography of the electropolished specimen. In order to maintain the original topography of the substrate in this manner, the penetration of the conversion coating solution species to the metal substrate through the initially deposited coating material probably proceeded at similar rates over the aluminium metal surface. Interestingly, the approximately linear features which have been described by other authors [17] as pathways through which solution species make contact with the substrate increased in width from about $5 \mathrm{~nm}$ for specimens treated for $30 \mathrm{~s}$ to $10 \mathrm{~nm}$ for specimens treated for $600 \mathrm{~s}$. Thinning of coatings formed in acidic solutions has been reported by some authors [5] and the solubility of oxides/hydroxides of Cr III and $\mathrm{Al}$ varies with $\mathrm{pH}$. While aluminium oxides may not be readily soluble at the $\mathrm{pH}$ regimes for the coating solution employed in this investigation, 1.6, $\mathrm{Cr}_{2} \mathrm{O}_{3} / \mathrm{Cr}_{2}(\mathrm{OH})_{3}$ is partially soluble. Thus, as a major component of the coating, thinning as a result of its solubility in acidic medium occurred.

The variation of coating thickness, assessed from ultramicrotomed sections, with immersion time is displayed in Figure 5, where the individual points represent the thickness determined from duplicate specimens treated for similar times. The growth rate of the coatings was initially rapid but decreased progressively with time. The decrease in rate was marked at $120 \mathrm{~s}$ treatment time. This may be partly due to the effects of general chemical thinning of the as formed coating in addition to shielding of the aluminium/coating interface from the coating solution species by newly formed coatings.

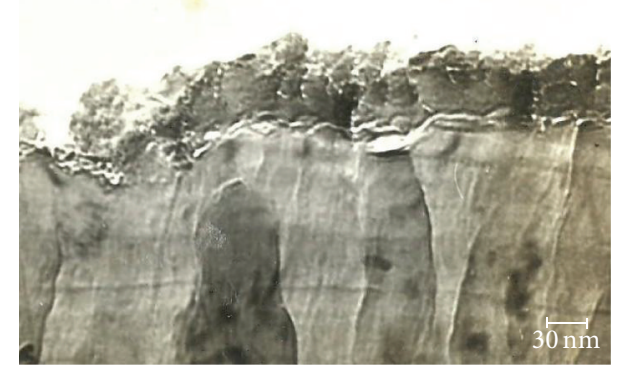

FIGURE 3: Transmission electron micrograph of ultramicrotomed section of the coating developed for $15 \mathrm{~s}$ on aluminium in a chromate bath.

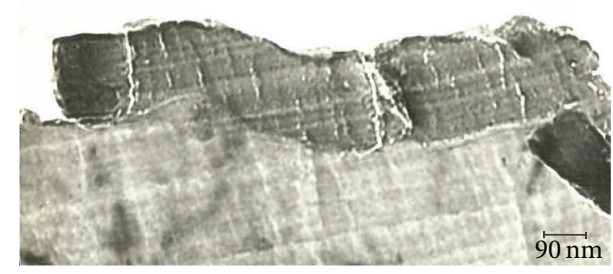

FIGURE 4: Transmission electron micrograph of ultramicrotomed section of aluminium specimen treated in chromate coating bath for $120 \mathrm{~s}$.

These phenomena will contribute to the decrease in the rate of coating growth during the extended treatment periods. Though shielding is envisaged, the approximately linear features, which are alternating pathways, extend through the coating material to near the metal/coating interface, whereby "active" aluminium substrates interact with the environment.

3.4. Elemental Analysis. For all specimens examined, the EDX attachment in both the SEM and TEM indicates $\mathrm{Al}$ and $\mathrm{Cr}$ as the principal components of the coatings; however, $\mathrm{Cu}$ $\mathrm{X}$-ray yield from the copper grid employed in supporting ultramicrotomed sections for viewing in the TEM was also indicated. Aluminium X-ray was generated from the substrate in addition to those that were derived from the coatings per se. For chromium to be detected in the coatings developed after 15 to $30 \mathrm{~s}$ of treatment, shows that after relatively short immersion times, coatings developed over the macroscopic metal surface which at face value was composed initially of mainly aluminium species.

In general, typical EDX spectra generated from the specimens in the SEM show the presence of $\mathrm{Al}$ and $\mathrm{Cr}$ species as the prominent X-rays generated. The activation of aluminium substrate which was facilitated by the complexing action of fluoride species in the acidic coating bath was complimented by hydrogen evolution reaction as well as reduction of $\mathrm{Cr}^{6+}$ to $\mathrm{Cr}^{3+}$ as cathodic counterparts. Subsequent increase in the interfacial $\mathrm{pH}$ as a result of hydrogen evolution will encourage the deposition of $\mathrm{Cr}_{2}(\mathrm{OH})_{3}$ and/or $\mathrm{Cr}_{2}(\mathrm{O})_{3}$ as 


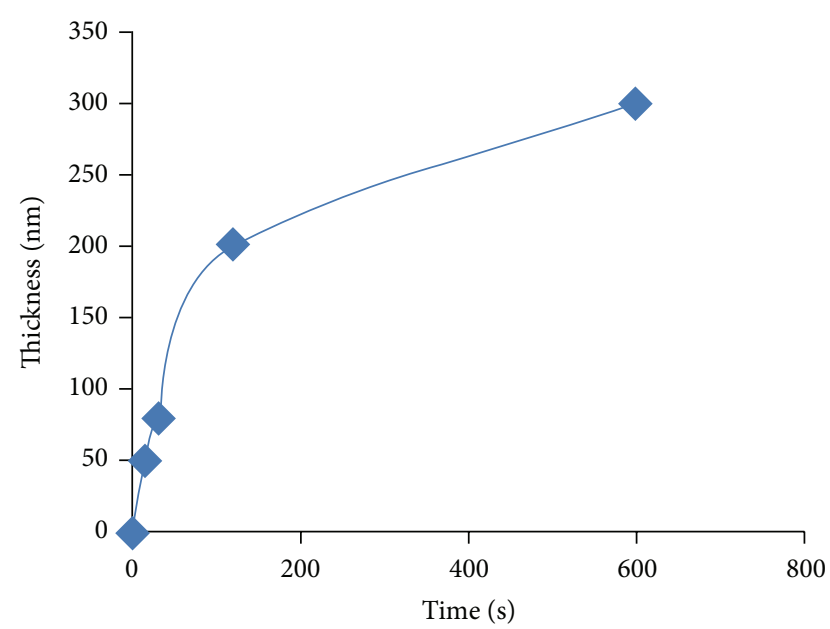

FIGURE 5: Coating thickness versus time of treatment in chromate coating bath.

well as aluminium oxide/hydroxide, both probably hydrated, depending on the solubility constants of the compounds. Thus the reactions leading to the formation of the coating can be summarised as follows:

$$
2 \mathrm{Al} \longrightarrow 2 \mathrm{Al}^{3+}+6 \mathrm{e}^{-}
$$

anodic reaction as a result of complexing action of $\mathrm{F}^{-}$.

The two cathodic reactions which occurred simultaneously are

$$
\begin{aligned}
& 3 \mathrm{H}^{+}+3 \mathrm{e}^{-} \longrightarrow{ }_{2}^{3} \mathrm{H}_{2} \\
& \mathrm{Cr}^{6+}+3 \mathrm{e}^{-} \longrightarrow \mathrm{Cr}^{3+}
\end{aligned}
$$

As hydrogen ions are consumed, the interfacial $\mathrm{pH}$ increases, which encourages the deposition of $\mathrm{Cr}_{2}(\mathrm{OH})_{3} / \mathrm{Cr}_{2} \mathrm{O}_{3}$ and $\mathrm{Al}_{2} \mathrm{O}_{3} / \mathrm{Al}_{2}(\mathrm{OH})_{3}$ mixed compounds, depending on their solubility constants.

$$
\begin{aligned}
& 2 \mathrm{Cr}^{3+}+3 \mathrm{OH}^{-} \longrightarrow \mathrm{Cr}_{2}(\mathrm{OH})_{3} \\
& 2 \mathrm{Al}^{3+}+3 \mathrm{OH}^{-} \longrightarrow \mathrm{Al}_{2}(\mathrm{OH})_{3}
\end{aligned}
$$

The concentration of $\mathrm{Cr}^{3+}$ will be more than for that of $\mathrm{Al}^{3+}$ in the presence of large quantities of reducible $\mathrm{Cr}^{6+}$ species. Hence chromium compounds will predominantly deposit on the metal as the coating material. Hence the greenish orange colouration observed on specimens treated for 1530 s suggests the initial formation chromium III compounds, which are notably green in colour, on to which chromium VI species are adsorbed or occluded within the growing coating. These dual sources of chromium will account for the $\mathrm{Cr}$ yield observed in the spectra.

Energy dispersive analysis of X-rays generated in the conventional mode in the transmission electron microscope, with nominal probe size of $10 \mathrm{~nm}$ to optimise spatial resolution and X-ray yield performed at various regions ranging from coating/solution to metal/coating interfaces, on selected specimens indicated $\mathrm{Al}$ and $\mathrm{Cr}$. Although under the operating conditions selected, spreading of electron beam by about $10 \%$ is anticipated; however, the $\mathrm{X}$-ray yields for $\mathrm{Cr}$ increased as the probe moved towards the coating/solution interface whereas those for $\mathrm{Al}$ increased as the probe positions moved towards the metal/coating interface which showed some contributions from the substrate. For chromium yields to increase in this manner indicate the migration of $\mathrm{Cr} \mathrm{VI}$ species into the film material through intercrystallite regions as well as ingress through the linear features in the coatings. For all specimens, the $\mathrm{Al}$ : $\mathrm{Cr}$ peak ratios did not vary significantly for a particular region of the coating. The ratio for coating materials near the coating/solution interface is about $1: 5$, within the coating section, and a ratio of about $1: 2$ is observable, whereas for coating materials at the metal/coating interface, the ratio is about $1: 0.4$. Although information regarding the chemical states of species is not forthcoming by the EDX techniques; however, from the ratios determined, it is apparent that adsorbed and/or penetrating $\mathrm{Cr}$ (VI) species contributed to the total X-ray yields detected in the outermost regions of the coatings. In addition, relatively light elemental analysis is not possible by the EDX technique; thus, the presence or otherwise of fluorine, hydrogen and oxygen cannot be ascertained. However, from both EDX techniques in the SEM and TEM, the coating is composed of chromium compounds laced with aluminium compounds which corroborates the findings of other various authors $[3,5,17,18]$ and will be described as either hydrated $\mathrm{Cr}_{2} \mathrm{O}_{3}$ and/or $\mathrm{Cr}_{2}(\mathrm{OH})_{3}$ containing some hydrated $\mathrm{Al}_{2} \mathrm{O}_{3}$.

\section{Conclusions}

(a) Chromate conversion coating on aluminium is composed of chromium compounds containing some aluminium oxide and/or hydroxide which are probably hydrated.

(b) Chromium VI species in the coating solution, apart from providing cathodic reactant for the deposition of chromium III compounds as the major coating materials, are incorporated into the growing conversion coating either by adsorption, occlusion, and/or gradual migration into the coating material through pathways in the coating.

(c) Within the regions of ultramicrotomed section examined in the CTEM, some of the linear pathways end at some short distances from the metal/coating interface, while newly established ones terminate close to the interface, thereby allowing interaction of "active" aluminium regions with the environment for coating development to occur. Thus, the growth of the coating depends on opening and blockage of pathways within the established coating materials.

(d) The outer surfaces of the coating are made up of clusters of spherical coating materials which can provide anchor sites for subsequently applied organic finishes thus complimenting the short ranged adhesive forces between two bonding surfaces. 
(e) Any replacement for chromate should possess the physical characteristics of CCC in addition to having leachable inhibitors within its coating material which can be released to stifle corrosion reactions at breached regions where the substrate may be transiently exposed to the environment.

\section{Acknowledgment}

The author acknowledges the Head of Centre, Corrosion and Protection Centre, School of Materials, The University of Manchester, UK, for the use of laboratory facilities.

\section{References}

[1] T. Chen, W. Li, and J. Cai, "Formation of a chrome-free and coloured conversion coating on AA6063 aluminium alloy," RSC Advances, vol. 1, no. 4, pp. 607-610, 2011.

[2] H. Bhatt, "Trivalent chromium conversion coating for corrosion protection of aluminium Surfaces," in Proceedings of the Department of Defence Corrosion Conference, pp. 1-61, Gaylord National, Washington, DC, USA, August 2009.

[3] K. Asami, M. Oki, G. E. Thompson, G. C. Wood, and V. Ashworth, "Composition of the near surface regions of conversion coated aluminium," Electrochimica Acta, vol. 32, no. 2, pp. 337343, 1987.

[4] A. M. Pereira, G. Pimenta, and B. D. Dunn, "A comparison of Alodine 1200 with chromium-free conversion coatings," in Assessment of Chemical Conversion Coatings for the Protection of Aluminium Alloys (ESA-STM-276), K. Fletcher, Ed., pp. 161, ESA Communication Production Office, Noordwijk, The Netherlands, 2008.

[5] J. H. Osborne, "Observations on chromate conversion coatings from a sol-gel perspective," Progress in Organic Coatings, vol. 41, no. 4, pp. 280-286, 2001.

[6] O. Lunder, J. C. Walmsley, P. MacK, and K. Nisancioglu, "Formation and characterisation of a chromate conversion coating on AA 6060 aluminium," Corrosion Science, vol. 47, no. 7, pp. 1604-1624, 2005.

[7] M. Oki, "Studies on chromium-free conversion coatings on aluminium," Journal of Applied Science and Environmental Management, vol. 11, no. 2, pp. 187-190, 2007.

[8] M. Zhao, S. Wu, P. An, Y. Fukuda, and H. Nakae, "Growth of multi-elements complex coating on AZ91D magnesium alloy through conversion treatment," Journal of Alloys and Compounds, vol. 427, no. 1-2, pp. 310-315, 2007.

[9] M. Kendig, M. Hon, and L. Warren, "'Smart' corrosion inhibiting coatings," Progress in Organic Coatings, vol. 47, no. 3-4, pp. 183-189, 2003.

[10] S. H. Wang, C. S. Liu, and F. J. Shan, "Corrosion behavior of a zirconium-titanium based phosphonic acid conversion coating on AA 6061 aluminium alloy," Acta Metallurgica Sinica, vol. 21, no. 4, pp. 269-274, 2008.

[11] M. W. Kendig and R. G. Buchheit, "Corrosion inhibition of aluminum and aluminum alloys by soluble chromates, chromate coatings, and chromate-free coatings," Corrosion, vol. 59, no. 5, pp. 379-400, 2003.

[12] M. Takai and M. Takaya, "Influence of conversion coating on magnesium and aluminum alloys by adhesion method," Materials Transactions, vol. 49, no. 5, pp. 1065-1070, 2008.
[13] J. Hu, X. H. Zhao, S. W. Tang, W. C. Ren, and Z. Y. Zhang, "Corrosion resistance of cerium-based conversion coatings on alumina borate whisker reinforced AA6061 composite," Applied Surface Science, vol. 253, no. 22, pp. 8879-8884, 2007.

[14] L. E. M. Palomino, I. V. Aoki, and H. G. de Melo, "Microstructural and electrochemical characterization of Ce conversion layers formed on $\mathrm{Al}$ alloy 2024-T3 covered with Cu-rich smut," Electrochimica Acta, vol. 51, no. 26, pp. 5943-5953, 2006.

[15] ASTM E 1558-09, "Standard guide for electrolytic polishing of metallographic specimens".

[16] M. Oki, "Morphology and composition of aluminium pretreated in sulphuric acid/dichromate solution," Indian Journal of Technology, vol. 27, no. 9, pp. 454-458, 1989.

[17] M. Oki and E. Charles, "Chromate conversion coating on Al-0.2 wt.\% Fe alloy," Materials Letters, vol. 63, no. 23, pp. 1990-1991, 2009.

[18] L. Xia and R. L. McCreery, "Chemistry of a chromate conversion coating on aluminum alloy AA2024-T3 probed by vibrational spectroscopy," Journal of the Electrochemical Society, vol. 145, no. 9, pp. 3083-3089, 1998. 

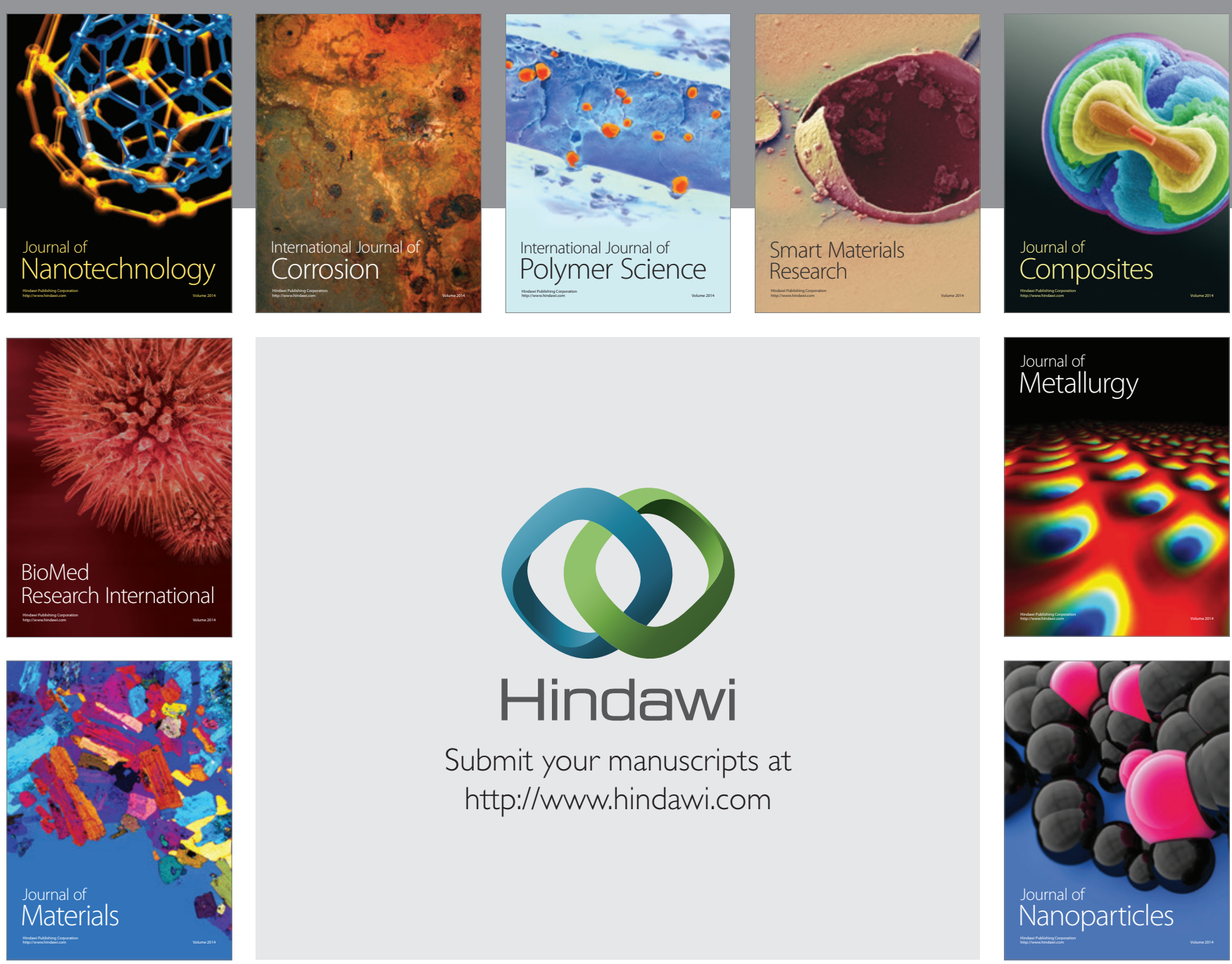

Submit your manuscripts at http://www.hindawi.com
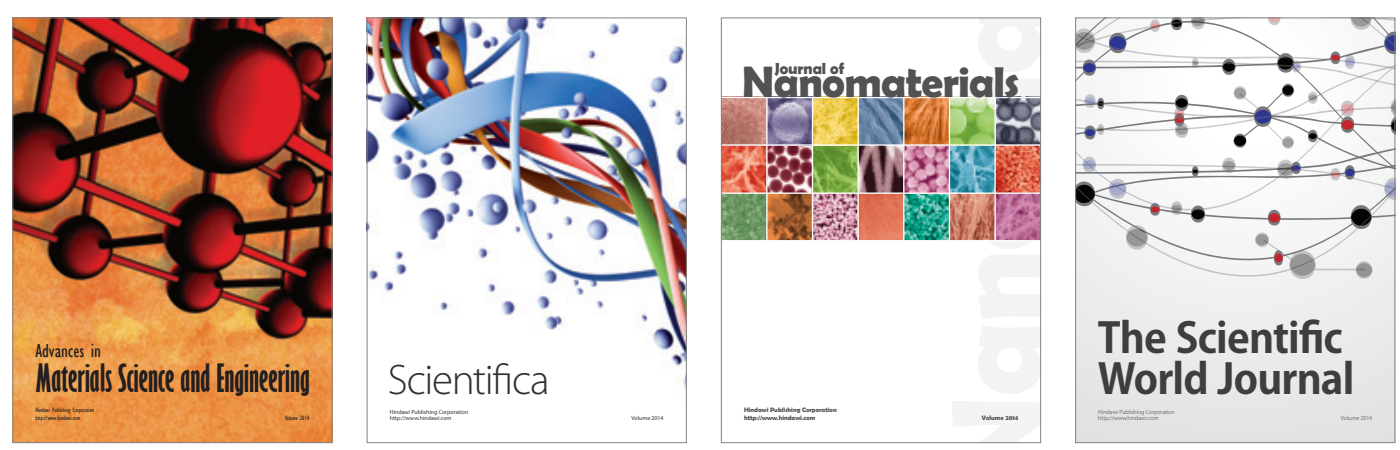

\section{The Scientific World Journal}
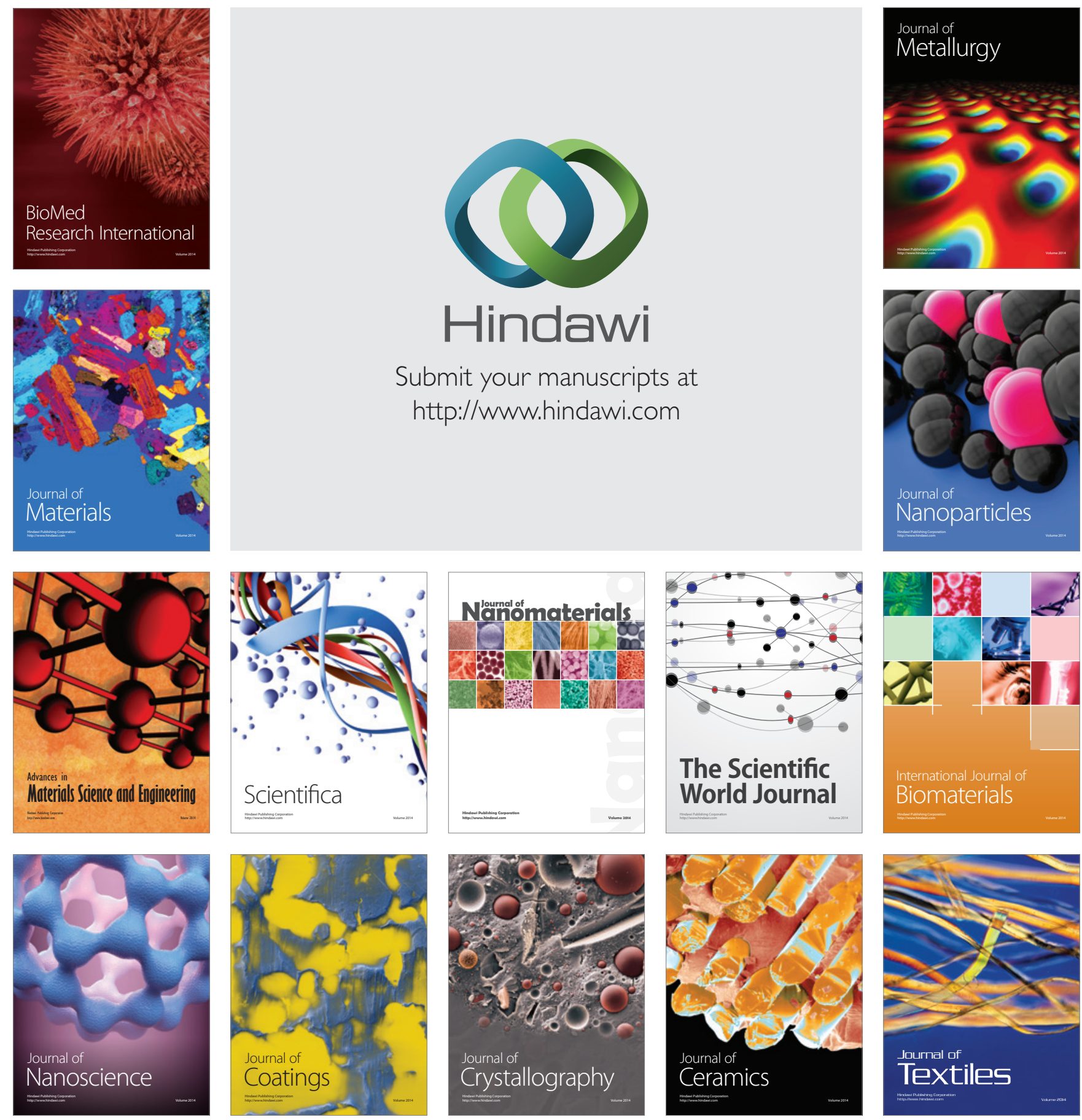